\title{
BMJ Open Erectile dysfunction and penile rehabilitation after pelvic fracture: a systematic review and meta-analysis
}

\author{
Florian A Schmid (D) , ${ }^{1}$ Ulrike Held (D) , ${ }^{2}$ Daniel Eberli, ${ }^{1}$ Hans-Christoph Pape, ${ }^{3}$ \\ Sascha Halvachizadeh (D) ${ }^{3}$
}

To cite: Schmid FA, Held U, Eberli D, et al. Erectile dysfunction and penile rehabilitation after pelvic fracture: a systematic review and meta-analysis. BMJ Open 2021;11:e045117. doi:10.1136/ bmjopen-2020-045117

- Prepublication history and additional supplemental material for this paper are available online. To view these files, please visit the journal online (http://dx.doi.org/10.1136/ bmjopen-2020-045117).

FAS and SH contributed equally.

Received 06 October 2020 Accepted 11 May 2021

Check for updates

(C) Author(s) (or their employer(s)) 2021. Re-use permitted under CC BY-NC. No commercial re-use. See rights and permissions. Published by BMJ.

${ }^{1}$ Department of Urology, University Hospital Zurich, University of Zurich, Zurich, Switzerland

${ }^{2}$ Department of Epidemiology, Biostatistics and Prevention Institute, University of Zurich, Zurich, Switzerland

${ }^{3}$ Department of Trauma, University Hospital Zurich, University of Zurich, Zurich, Switzerland

Correspondence to Dr. Sascha Halvachizadeh; Sascha.Halvachizadeh@usz.ch

\section{ABSTRACT}

Objective To investigate the rate of erectile dysfunction (ED) after pelvic ring fracture (PRF).

Design Systematic review and meta-analysis.

Methods A systematic literature search of the Cochrane, EMBASE, MEDLINE, Scopus and Web of Science Library databases was conducted in January 2020. Included were original studies performed on humans assessing ED after PRF according to the 5-item International Index of Erectile Function (IIEF-5) questionnaire and fracture classification following Young and Burgess, Tile or Arbeitsgemeinschaft für 0steosynthesefragen/Orthopedic Trauma Association. Furthermore, interventional cohort studies assessing the effect of penile rehabilitation therapy with phosphodiesterase-5-inhibitors (PDE-5-I) on IIEF- 5 scores compared before and after treatment were included. Results were presented as forest plots of proportions of patients with ED after PRF or mean changes on IIEF- 5 questionnaires before and after penile rehabilitation. Studies not included in the quantitative analysis were narratively summarised. Risk of bias assessment was conducted using the revised tool for the Quality Assessment on Diagnostic Accuracy Studies.

Results The systematic literature search retrieved 617 articles. Seven articles were included in the qualitative analysis and the meta-analysis. Pooled proportions revealed $37 \%$ of patients with ED after suffering any form of PRF (result on probability scale $\mathrm{pr}=0.37,95 \% \mathrm{Cl}$ : 0.26 to 0.50 ). Patients after 3 months of penile rehabilitation therapy reported a higher IIEF-5 score than before (change score $=6.5$ points, $95 \% \mathrm{Cl}$ : 2.54 to 10.46 , p value $=0.0013$ ). Conclusion Despite some heterogeneity and limited high-quality research, this study concludes that patients suffering from any type of PRF have an increased risk of developing ED. Oral intake of PDE-5-I for the purpose of penile rehabilitation therapy increases IIEF- 5 scores and may relevantly influence quality-of-life in these patients. PROSPERO registration number CRD42020169699.

\section{INTRODUCTION}

Pelvic ring fractures (PRFs) result from highenergy injuries and are associated with devastating acute and chronic complications as severe and life-threatening haemorrhage or chronic pain and impaired ambulation. ${ }^{1-5}$ The initial treatment of PRF is guided by the fracture morphology, pathophysiologic

\section{Strengths and limitations of this study}

- Despite the strict definition of pelvic ring fracture (PRF) and erectile dysfunction (ED), there is still an inevitable variability due to the heterogeneous methodological nature of available studies and study populations from different centres worldwide.

- Resulting from the lack of standardisation, a broad variety of classifications for PRF and different definitions and questionnaires for the evaluation of ED were used.

- Included studies provide a certain risk of bias.

The included results were consistent across studies.

reaction of the organism to the trauma and concomitant injuries. ${ }^{6-9}$ After initial haemodynamic stabilisation and fixation of the PRF, an interdisciplinary team-approach aims to improve long-term outcomes and to reduce complications. ${ }^{10}{ }^{11}$ In male patients suffering PRF, erectile dysfunction (ED) is one of the main long-term complications. ED ranks among the adverse effects after PRF that severely impair the quality-of-life (QoL) in these patients, especially when urogenital damage is involved. ${ }^{12-14}$ The treatment of ED depends on the underlying pathogenesis and on patient-specific factors-it ranges from psychological behaviour therapy and pharmacological support until surgical interventions. ${ }^{15}$ The incidence of ED after PRF varies across the published literature due to a lack of epidemiologic studies investigating this subject, indicating a high number of unreported cases. It further remains unclear what the consequences of ED after PRF in the young male population is and whether patients with PRF benefit from early pharmacological penile rehabilitation therapy with phosphodiesterase-5-inhibitors (PDE-5-I). Therefore, this meta-analysis aims to answer the following questions: (a) Is the incidence of ED associated with the severity of PRF? and (b) What is the treatment effect of penile 
rehabilitation after PRF with the help of PDE-5-I? We hypothesise that the rate of $\mathrm{ED}$ is associated with the increasing severity of PRFs and that pharmacological penile rehabilitation improves blood circulation in the pelvic organ region and therefore reduces the chances of persistent ED.

\section{METHODS}

This study was conducted following the Preferred Reporting Items for Systematic Reviews and Meta-Analyses (PRISMA) guidelines. ${ }^{1617}$ It was recorded on PROSPERO, the prospective register of systematic reviews.

\section{Search strategy and definitions}

A scientific librarian and information expert, specialised in medical research, conducted a systematic literature search of the Cochrane, EMBASE, MEDLINE, Scopus and Web of Science Library databases in January 2020. PRFs are classified following Young and Burgess, ${ }^{18}$ Tile $^{19}$ or the Arbeitsgemeinschaft für Osteosynthesefragen/Orthopedic Trauma Association classification. ${ }^{20} \mathrm{ED}$ was evaluated based on the 5-item International Index of Erectile Function (IIEF-5) questionnaire. ${ }^{21}{ }^{22}$ Presence of ED was defined as a score between 5 and 21 (severe-mild ED) according to results on IIEF-5 questionnaires. Categorisation according to the achieved IIEF-5 score leads to the following subgrouping: 'Severe' (5-7 points), 'moderate' (8-11 points), 'mild to moderate' (12-16 points), 'mild' (17-21 points) and 'no' (22-25 points) ED. ${ }^{23}$ The term 'penile rehabilitation' refers to the treatment of ED with PDE-5-I. Penile rehabilitation is a urological concept to enhance ED in patients after nerve-sparing radical prostatectomy due to prostate cancer. The idea of this treatment is to enhance blood circulation in the postoperative period (3-6 months) after the intervention to ameliorate neurovascular regeneration and to avoid cavernous fibrosis. Although penile rehabilitation has been subject to some debate, this concept might be also helpful in young male patients after trauma to the pelvis. PRFs frequently lead to damage in the neurovascular structures of the pelvis. As a consequence, male patients may experience ED and therefore a severely reduced QoL.

\section{Inclusion/exclusion criteria}

Inclusion criteria were original studies performed on humans assessing ED after PRF written in French, Spanish, Italian, German and English language. No specific time limits were used. To increase comparability, we only included articles that assessed ED based on IIEF- 5 and classified the severity of PRF accordingly (see above). We included interventional cohort studies assessing the effect of PDE-5-I on ED after PRF with the reported change of the IIEF-5 scores prior and after PDE-5-I treatment as main outcome parameter. Articles assessing secondary ED after treatment of urethral injuries were excluded. Furthermore, articles without full-text availability were excluded. Case reports, case series, narrative reviews, expert opinions, editorials, book chapters, conference abstracts, letters, commentaries, correspondences, in vitro and animal experiments were completely excluded from the systematic review. The full search string is shown in the online supplemental file.

\section{Data management}

The export of de-duplicated publications from all sources were saved in an EndNote library. Two authors (FAS and $\mathrm{SH}$ ) received the same library and independently screened and assorted all articles within the publicly available web-tool Rayyan. ${ }^{24}$

\section{Study selection}

According to the PRISMA flow diagram, steps of screening were performed as follows ${ }^{16}$ : (1) title and abstract screening, (2) full-text screening, (3) extraction and storage of data and (4) qualitative and quantitative evidence synthesis. After title and abstract screening, full texts were obtained for formal inclusion or exclusion into our systematic review. Full text analysis was performed independently by two authors (FAS and $\mathrm{SH}$ ). Discrepancies were resolved by consensus or, if necessary, until consensus was reached. Studies that did not provide the type of PRF and the subsequent proportion of patients with ED, as well as no baseline scores of IIEF-5 questionnaires (before PDE-5-I therapy) for the evaluation of penile rehabilitation, were not included in the quantitative analysis. However, some of these studies were summarised in a narrative way.

\section{Data extraction}

The following data were extracted from published articles: (1) general study information: author, year, country and study design (ie, prospective or retrospective); (2) patient characteristics: sample size, age, type of pelvic injury (category) and follow-up time (months); (3) outcome: rate of patients with ED (proportion), mean or median IIEF-5 score (absolute values) either after trauma and follow-up or before and after treatment and IIEF-5 category (categorical values); (4) associated injuries: urogenital injuries (proportion) or urethral injury (proportion), other injury sites (amount) and (5) treatment: medication (type of PDE-5-I), dosage (mg) and treatment duration (months).

The data were extracted independently and in duplicate by two authors (FAS and $\mathrm{SH}$ ) on separate copies of an Excel spreadsheet. These were compared and discrepancies were resolved by consensus.

\section{Risk of bias}

Risk of bias assessment was conducted using the revised tool for the Quality Assessment on Diagnostic Accuracy Studies. ${ }^{25}$ Each study was assessed for risk of bias through four key domains: patient selection, usage of standardised IIEF-5 questionnaires, grouping into internationally accepted pelvic fracture classifications, and flow and timing. For each domain, the two authors (FAS and SH) independently assigned a rating of low, high or unclear 
risk of bias. Again, discrepancies were resolved through discussion or until consensus was reached.

\section{Statistical analysis}

Descriptive statistics on study level were reported as mean values and proportions. For evidence synthesis for continuous outcomes, mean values with SDs were used for pooling in a random effects model. If studies reported mean values with SEs, the SD was computed using the formula provided by the Cochrane collaboration: $\mathrm{SD}=\mathrm{SE} \times \sqrt{ } \mathrm{N} .{ }^{26}$ For studies which reported values as median with range or IQR, we estimated the mean and SD according to the formulas by Wan $e t a l .{ }^{27}$ To confirm the reliability of these estimations, we performed them in duplicate using the formulas by Luo et al, ${ }^{28}$ and compared the results of the two methods. Both methods have in general shown good reliability for these estimations, even in presence of deviation from the normal distribution. ${ }^{29}$ Evidence synthesis for binary outcomes was done by dividing reported numbers of patients with the condition over total number of patients in each study, and these proportions were used for pooling in a random effects logistic regression model. The random effects model computes exact $95 \%$ CIs based on the binomial distribution for the overall effect.

Results were presented as forest plots of mean changes of IIEF- 5 questionnaires before and after penile rehabilitation, or proportions of patients with ED including $95 \%$ CI. In one forest plot, studies were ordered by subtypes of PRFs. To quantify heterogeneity, the Q-test (total betweenstudy variance), $I^{2}$-statistic (proportion of total variation) and $H^{2}$-statistic (ratio of total amount of variability and amount of sampling variance) was calculated for all metaanalyses. All statistical analyses were performed using R (V.3.4.2) ${ }^{30}$

\section{Patient and public involvement}

No patient involved.

\section{RESULTS}

\section{Study selection and characteristics}

According to the systematic literature research and after removal of duplicates, 617 articles were found. The initial screening process for title and abstract excluded 556 articles. The full-text analysis of the remaining 61 articles led to the exclusion of further 54 articles. We included four articles assessing the incidence of ED after PRF based on IIEF-5 and three articles investigating the treatment effect of PDE-5-I on ED after PRF (figure 1). Articles included for qualitative and quantitative analysis were published between the years 2000 and 2019 and were all retrospective cohort studies (table 1).

\section{Incidence of ED after PRF}

The analysis for the incidence of ED after PRF included 181 male patients with mean age 42 years. Of these, 65 patients (35.9\%) reported ED based on IIEF-5 score of

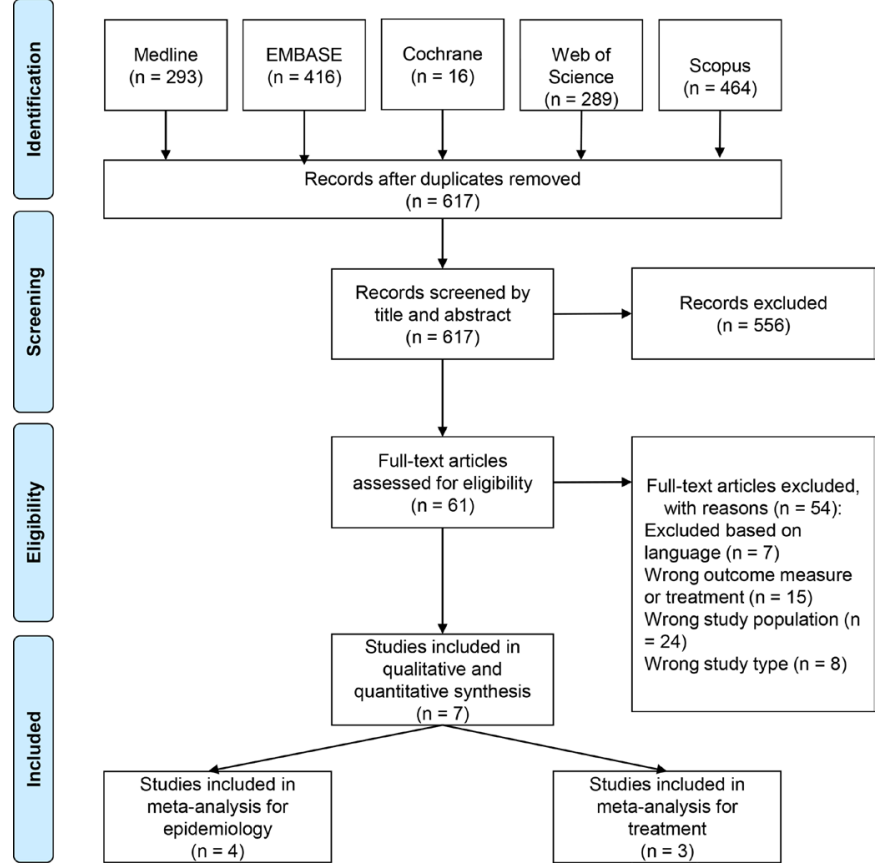

Figure 1 Preferred Reporting Items for Systematic Reviews and Meta-Analyses flow diagram of study selection.

$\leq 21$ points. The mean follow-up was $24.01 \pm 10.91$ months. The overall mean IIEF-5 score was $20.01 \pm 2.01$ points. The rate of ED after anterior-posterior compression (APC) fracture or type A fractures was $29.27 \%$. The rate of ED after lateral compression (LC) or type B PRF was $17.86 \%$. After vertical shear (VS) or type C PRF $48 \%$ of patients suffered from ED. PRF with associated pelvic fracture urethral injury (PFUI) led to a higher percentage of ED than PRF without PFUI (58.6\% vs $38.1 \%$ ). Pooling the proportions with the random-effects model resulted in 37\% of patients with ED after suffering any form of PRF (result on probability scale pr $=0.37,95 \%$ CI: 0.26 to $0.50)$. As a measure of heterogeneity, the percentage of variability $\left(I^{2}\right)$ was moderate with $44.2 \%$ (p value $=0.021$ )

Elevated probabilities for the development of ED after PRF was described in Tile fractures types B and C (pr=0.62; 95\% CI: 0.28 to 0.87 and pr $=0.80 ; 95 \%$ CI: 0.31 to 0.97 , respectively) as well as with injuries associated with PFUI ( $p r=0.59 ; 95 \%$ CI: 0.40 to 0.75). Duramaz et al reported higher proportions of ED in patients with APC and VS ( $p r=0.42 ; 95 \%$ CI: 0.18 to 0.69 and $p r=0.40$; 95\% CI: 0.21 to 0.62 , respectively) compared with LC fractures (pr $=0.02 ; 95 \%$ CI: 0.00 to 0.29 ) according to Young and Burgess. Fanjalalaina Ralahy et al reported the highest proportion of ED with $80 \%$ of patients affected after PRF Tile C ( $\mathrm{pr}=0.80 ; 95 \%$ CI: 0.31 to 0.97 ). The lowest proportion of ED was demonstrated by Duramaz et al in LC fractures with $0 \%$ of patients developing ED after a follow-up of 27 months (pr=0.02; 95\% CI: 0.00 to 0.29 ). Furthermore, the type A fractures presented by Fanjalalaina Ralahy et $a l$ and the overall chances to develop ED in a combined group of A, B and C fractures from Malavaud reported all lower probabilities than the 
Table 1 Included articles

\begin{tabular}{|c|c|c|c|c|c|c|c|}
\hline Author & Year & Country & Study design & $\mathbf{N}$ & $\begin{array}{l}\text { Mean age, } \\
\text { years (range) }\end{array}$ & Inclusion & Main result \\
\hline Nieto & 2017 & Mexico & $\begin{array}{l}\text { Retrospective } \\
\text { cohort study }\end{array}$ & 8 & $32.5(26-56)$ & $\begin{array}{l}\text { Treatment } \\
\text { effect PDE- } \\
5-1\end{array}$ & $\begin{array}{l}\text { Nearly all patients }(87.5 \%) \\
\text { had a positive effect on IIEF- } \\
5 \text { questionnaires after penile } \\
\text { rehabilitation treatment with } \\
\text { tadalafil } 5 \text { mg for } 3 \text { months. }\end{array}$ \\
\hline Peng & 2015 & China & NFS & 28 & $34(22-49)$ & $\begin{array}{l}\text { Treatment } \\
\text { effect PDE- } \\
5-1\end{array}$ & $\begin{array}{l}\text { Almost two-thirds of the } \\
\text { patients }(61.5 \%) \text { witnessed a } \\
\text { positive effect on IIEF- } 5 \text { scores } \\
\text { after penile rehabilitation with } \\
\text { sildenafil } 50 \text { mg for } 3 \text { months. }\end{array}$ \\
\hline Duramaz & 2019 & Turkey & $\begin{array}{l}\text { Retrospective } \\
\text { cohort study }\end{array}$ & 52 & 35 (19-50) & $\begin{array}{l}\text { Incidence } \\
\text { of ED after } \\
\text { PRF }\end{array}$ & $\begin{array}{l}\text { Vertical shear injuries were the } \\
\text { most common type of PRF } \\
\text { in patients who suffered ED } \\
\text { according to IIEF- } 5 \text { scores. }\end{array}$ \\
\hline $\begin{array}{l}\text { Fanjalalaina } \\
\text { Ralahy }\end{array}$ & 2019 & Madagascar & $\begin{array}{l}\text { Retrospective } \\
\text { cohort study }\end{array}$ & 42 & $39.6(18->66)$ & $\begin{array}{l}\text { Incidence } \\
\text { of ED after } \\
\text { PRF }\end{array}$ & $\begin{array}{l}\text { One in three patients (33.3\%) } \\
\text { suffered ED following PRF } \\
\text { according to IIEF-5 scores. }\end{array}$ \\
\hline Malavaud & 2000 & France & $\begin{array}{l}\text { Retrospective } \\
\text { cohort study }\end{array}$ & 37 & $37.8(16-76)$ & $\begin{array}{l}\text { Incidence } \\
\text { of ED after } \\
\text { PRF }\end{array}$ & $\begin{array}{l}\text { Nearly one in three patients } \\
(29.7 \%) \text { reported ED following } \\
\text { PRF according to IIEF-5 scores. }\end{array}$ \\
\hline
\end{tabular}

ED, erectile dysfunction; IIEF-5, International Index of Erectile Function-5; n, number of patients; NFS, not further specified; PDE-5-I, phosphodiesterase-5 inhibitor; PRF, pelvic ring fracture.

studies of comparison ( $\mathrm{pr}=0.24 ; 95 \% \mathrm{CI}: 0.12$ to 0.43 and $\mathrm{OR}=0.30 ; 95 \% \mathrm{CI}: 0.17$ to 0.46 , respectively). For overall results, please see forest plot in figure 2.

\section{Effect of penile rehabilitation in patients with PRF}

Three studies with cumulative 67 patients investigated the effect of penile rehabilitation using PDE-5-I for the treatment of ED after PRF with concomitant PFUI. The mean age of patients across studies was 33 years. Either sildenafil $(50 \mathrm{mg})$ or tadalafil $(5 \mathrm{mg})$ were used for a treatment duration of 3 months. The mean IIEF-score after PRF and before treatment was $6.69 \pm 1.16$ points and increased to $13.3 \pm 4.5$ points after PDE-5-I treatment.

\begin{tabular}{|c|c|c|c|c|c|c|c|}
\hline Injury & Author & Year & Country & $\mathbf{N}$ & Months of Follow-up & & Proportion $[95 \% \mathrm{Cl}]$ \\
\hline$A B C$ & Malavaud & 2000 & France & 37 & 26.8 & $\mapsto$ & $0.30[0.17,0.46]$ \\
\hline A & Fanjalalaina & 2019 & Madagascar & 29 & 12.5 & $\mapsto$ & $0.24[0.12,0.43]$ \\
\hline B & Fanjalalaina & 2019 & Madagascar & 8 & 12.5 & & $0.62[0.28,0.87]$ \\
\hline C & Fanjalalaina & 2019 & Madagascar & 5 & 12.5 & & $0.80[0.31,0.97]$ \\
\hline APC & Duramaz & 2019 & Turkey & 12 & 27 & $\longrightarrow$ & $0.42[0.18,0.69]$ \\
\hline LC & Duramaz & 2019 & Turkey & 20 & 27 & 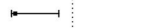 & $0.02[0.00,0.29]$ \\
\hline VS & Duramaz & 2019 & Turkey & 20 & 27 & $\longrightarrow$ & $0.40[0.21,0.62]$ \\
\hline no_PFUI & Chung & 2018 & USA & 21 & 56.4 & $\longmapsto$ & $0.38[0.20,0.60]$ \\
\hline PFUI & Chung & 2018 & USA & 29 & 46.8 & $\longmapsto$ & $0.59[0.40,0.75]$ \\
\hline \multirow[t]{2}{*}{ RE Model } & \multirow{2}{*}{\multicolumn{2}{|c|}{$\left(Q=18.01, p=0.021 ; I^{2}=44.2 \%, H^{2}=1.8\right)$}} & & 181 & & & $0.37[0.26,0.50]$ \\
\hline & & & & & & 1 & ᄀ \\
\hline
\end{tabular}

Figure 2 Weighted forest plot displaying the proportion of patients developing ED according to PRF classification. ABC, Tile A, $B$ and $C$ fractures; APC, anterior-posterior compression; ED, erectile dysfunction; LC, lateral compression; PFUI, pelvic fracture urethral injury; PRF, pelvic ring fracture; VS, vertical shear according to Young and Burgess. 


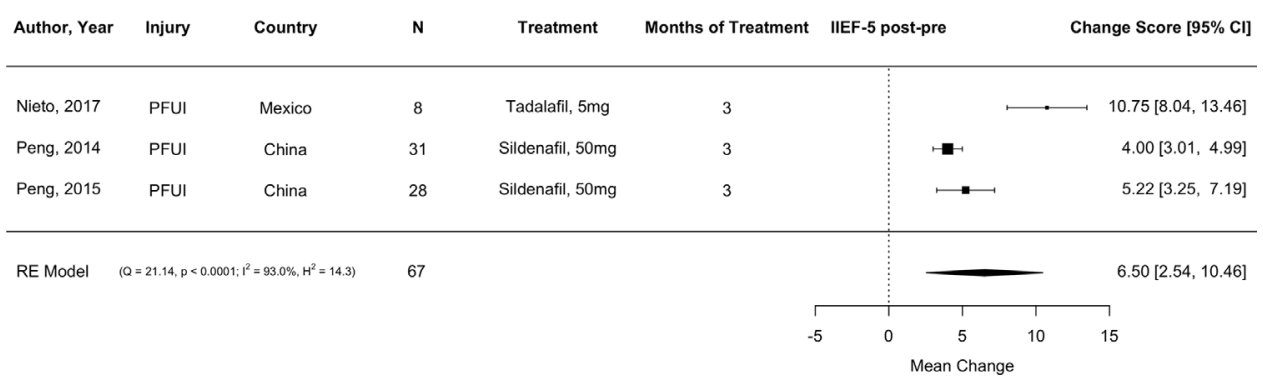

Figure 3 Forest plot displaying the treatment effect as mean change score between IIEF- 5 scores before and after penile rehabilitation treatment with PDE-5-I. IIEF-5, International Index of Erectile Function-5; PDE-5-I, phosphodiesterase-5-inhibitors; PFUI, pelvic fracture urethral injury.

There was strong evidence that the IIEF-5 score in patients after penile rehabilitation therapy was higher than the IIEF-5 score before treatment (change score $(\mathrm{CS})=6.5$ points increase, $95 \%$ CI: 2.54 to 10.46 , $p$ value $=0.0013)$. The largest difference in IIEF- 5 scores before and after 3 months of tadalafil treatment $(5 \mathrm{mg})$ was reported by Nieto et al (CS=10.75, 95\% CI: 8.04 to 13.46). Peng et al published in 2014 the smallest effect of penile rehabilitation therapy after 3 months of sildenafil $(50 \mathrm{mg})$ with a statistically higher IIEF score, comparing before and after treatment (CS=4.00, 95\% CI: 3.01 to 4.99$)$. A considerable heterogeneity was observed between the studies in this meta-analysis, justifying the use of a random-effects model $\left(I^{2}=93 \%, \mathrm{p}<0.0001\right)$. For summarised results, please see forest plot in figure 3 .

\section{Study quality}

The assessment of study quality is depicted in figure 4 . The overall quality of the included studies was low due to a rather high risk of bias. We found selection bias to be a concern for more than half of the included studies. This was due to studies not following consecutive recruitment, no or partial definition of inclusion and exclusion criteria as well as time and/or place of recruitment. Either no or only sparse information was available on the different types of fractures that were subdivided into groups of internationally accepted classifications. Finally yet importantly, flow and timing of the study was associated with a high risk of bias in almost all cases, except for Fanjalalaina Ralahy et al. ${ }^{31}$

\section{DISCUSSION}

PRF resulting from high-energy trauma is associated with increased mortality, ${ }^{3}$ impaired QoL $^{32-34}$ and concomitant injuries of pelvic organs. ${ }^{35}$ Among other adverse effects, $\mathrm{ED}$ is an underestimated functional complication in male patients after PRF. ${ }^{36}$ The aim of this article was to assess the rate of ED after PRF and the effect of pharmacological penile rehabilitation with PDE-5-I on assessed, standardised IIEF-5 questionnaires. The following two points can be regarded as quintessence of this systematic review and the underlying meta-analysis: (a) male patients after PRF have a significant risk (37\%) of developing any form of ED according to IIEF-5 scores, independent of injury severity and (b) pharmacological penile rehabilitation with PDE-5-I improves the individual IIEF-5 score by 6.5 points after a consecutive treatment of 3 months following injury in a male cohort with PRF and PFUI.

\section{Rate of ED after PRF}

The rate of ED after PRF is subject of substantial research activities. In one of the first published articles dealing with this topic in 1975, King ${ }^{37}$ reviewed 90 patients and noted an incidence of 5\%-42\% of ED after pelvic trauma, already claiming that ED was more commonly associated

A

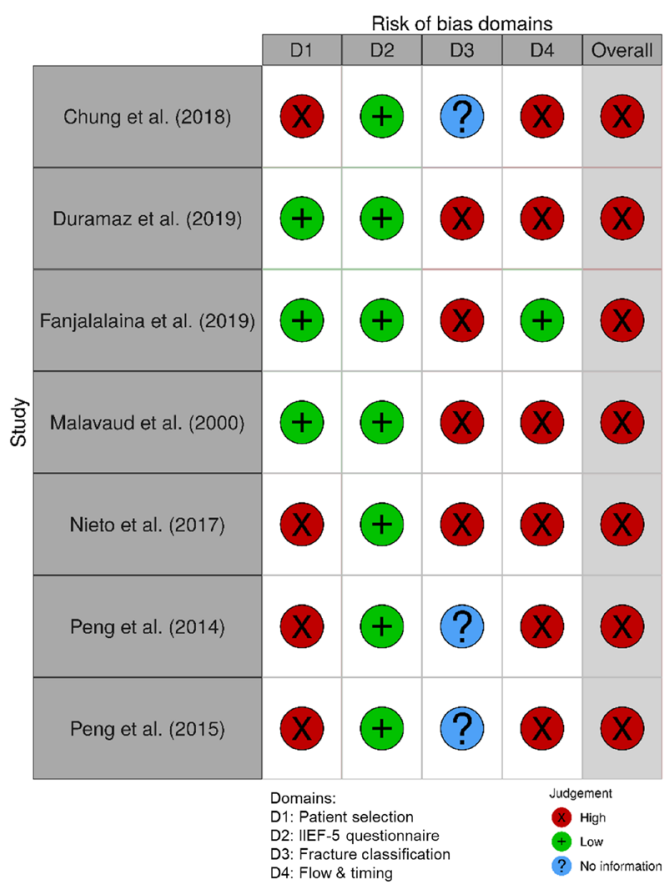

B

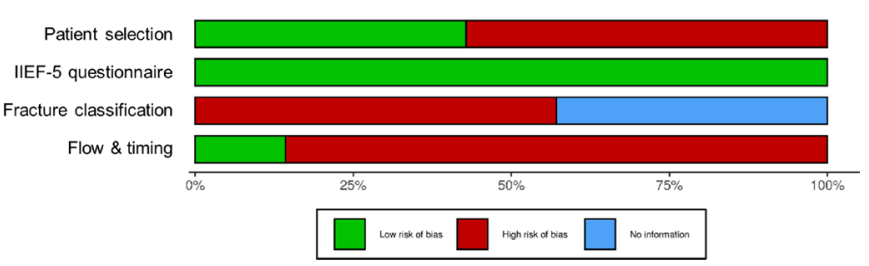

Figure 4 Domains in risk of bias of all included studies according to QUADAS-2 tool. (A) Traffic light plot and (B) weighted summary plot. IIEF-5, International Index of Erectile Function-5; QUADAS, Quality Assessment on Diagnostic Accuracy Studies. 
with concomitant urethral injury. In 2007, Metze et $a l^{88}$ investigated the rate of ED after PRF in 77 men using a long version of the IIEF questionnaire for evaluation. They reported $61 \%$ of patients with limitations in sexual function, $19 \%$ with persistent impairment and an increased risk of persistence with associated posterior ring disruptions (Tile fracture $\mathrm{C}$ ). The IIEF is known to be a simple questionnaire that meets established criteria, is consistent and reliable regarding test-retest reproducibility. Its validity to evaluate improvement of $\mathrm{EF}$ after $\mathrm{ED}$ treatment is further justified. ${ }^{39}$ Another study noted the rate of moderate and severe ED based on the IIEF-5 score to be $46.1 \%$, increasing in line with the complexity of the fractures (Tile fractures B and C), whereas mild and moderate forms of ED were present in 53.9\% of patients affected from type A fractures. ${ }^{40} \mathrm{~A}$ recent publication concluded, similar to our observed results, that APC and VS fractures according to Young and Burgess are more associated with ED in men and sexual dysfunction in both sexes, than LC fractures. ${ }^{41}$ In a review article from Harwood et $a l^{42}$ the rate of ED after pelvic fractures without PFUI ranges from $5 \%$ to $24 \%$ and from $9 \%$ to $72 \%$ with PFUI. They discussed the broad variance of assessment tools for ED as well as concomitant injuries as relevant reasons for the broad variability of the gathered data. ${ }^{42}$ Several studies investigated the pathogenesis of ED following pelvic fractures, identifying vasculogenic, ${ }^{43-47}$ neurogenic ${ }^{43-46} 48$ and psychogenic $^{44} 47$ etiologies. One of the most commonly investigated risk factor for developing ED following PRF is the presence and severity of urethral injuries as collateral damage. ${ }^{13464950}$ However, the management and the relevance of early versus delayed surgical or conservative treatment approaches after PFUI is still controversially discussed. ${ }^{51-54}$ Excluding PFUI, this study concludes an incidence of ED based on standardised IIEF-5 questionnaires of $41.5 \%$ ranging from $29.7 \%$ to $71.4 \%$, whereas the broad variance of incidence is mostly depending on injury severity. According to our meta-analysis, there is a visible trend for an increased rate of ED among higher classifications of PRF injuries. The severity of PRFs are associated with concomitant injuries such as vascular, ${ }^{55}$ nerve $^{56}$ as well as abdominal and urogenital organ damage. ${ }^{35}$ Wright et $a b^{57}$ identified that patients with sacroiliac fractures to have at least a four times higher risk for sexual and excretory dysfunction. Furthermore, it has been demonstrated, that patients suffer from a decreased QoL after more severe forms of PRFs. ${ }^{33} 5859$ All these risk factors, including higher trauma energy, are therefore associated with the development of persistent ED. ${ }^{4260}$

\section{Treatment of ED after PRF}

Strategies to treat ED as a consequence of PRF include pharmacological, mechanical and invasive treatment approaches. Initial attempts in Italy used papaverine and prostaglandin E1 as vasodilatative, intracavernous injections. ${ }^{61}$ In 2004, Shenfeld et a ${ }^{62}$ treated patients with ED after PFUI with $100 \mathrm{mg}$ oral sildenafil (PDE-5-I) on demand for 3-6 months. Forty-seven percent responded favourably to treatment, of which one-third reported resumption of normal spontaneous erections during the follow-up of 18 months. Oral PDE-5-I therapy is regarded as standard of care and serves as initial reference treatment in men suffering from ED. ${ }^{63-65}$ Both sildenafil and tadalafil are commonly used representatives of PDE5-I in the treatment of ED with comparable safety and efficacy. ${ }^{66}$ The management of concomitant injuries following PRF includes the early diagnostics and exclusion or treatment of organic damages to prevent or reduce the risk of ED. ${ }^{131442}$ According to the results of our meta-analysis, the treatment with PDE-5-I increases the IIEF- 5 score by 6.5 points in patients with ED after PRF with urethral injury. However, it remains unclear whether it also supports the permanent recovery of spontaneous erectile function. Similarly, the data for the efficacy of penile rehabilitation after radical prostatectomy are still controversially discussed. ${ }^{67} 68$ The effect seems to be ameliorated with a regular treatment regime compared with on-demand use of PDE-5-I in patients with ED after radical prostatectomy. ${ }^{69}$ The current limited evidence demonstrates, that daily oral intake of PDE-5-I seems to have also a relevant positive effect on ED in 55\%-88\% of patients after PRF with or without associated PFUI. ${ }^{70-73}$ Furthermore, the efficacy of pharmacological therapy can also be supported with mechanical aids, such as the use of vacuum erection devices or low-intensity shock-wave therapy. Both have shown to ameliorate IIEF-5 score and erection quality when used in combination with PDE-5-I, compared with stand-alone treatment. ${ }^{74-76}$ Finally, the implantation of penile prosthesis or revascularisation surgery are both regarded as last resort options in ED treatment of patients after perineal or pelvic surgery or trauma. ${ }^{77}$

\section{Limitations and strengths}

This systematic review and its meta-analysis have some limitations. Despite the strict definition of PRF and ED, all of the included studies present an inevitable variability due to their heterogeneous methodology and study populations coming from different centres worldwide. Therefore and due to the lack of standardisation, a broad variety of PRF classifications and different definitions as well as questionnaires for the evaluation of ED were used. Furthermore, all of the included studies provide a considerable risk of bias (figure 4). In addition, there are general limitations to systematic reviews regarding the search algorithm and the potential to miss relevant articles (selection bias, publication bias, language bias, time lag bias, etc). However, all of the included studies showed consistent and overall comparable outcomes, which implicates a representative cohort with reliable and repeatable results included in this analysis.

\section{CONCLUSION}

Patients who suffer from PRF have an increased risk of developing ED, regardless of the classification severity and the concomitant injuries. Early beginning of penile 
rehabilitation with the pharmacological help of PDE-5-I on a daily basis and a treatment duration of at least 3 months may relevantly reduce ED after PRF and therefore ameliorate QoL in these patients.

\section{Twitter Florian A Schmid @Schmid_FA}

Acknowledgements We thank Dr. sc. nat. Martina Gosteli, scientific librarian at the main library from the University of Zurich (Switzerland), for her precious efforts in performing a profound systematic literature research regarding the topic.

Contributors FAS and SH: contributed equally to this work. They developed the research idea and led the research team; both authors screened independently all articles, and found consent in cases of disagreement, both authors extracted and analysed the data. They wrote the original draft of the manuscript. UH: supported and supervised the methodology and the statistical analysis of the meta data. $\mathrm{UH}$ : read and reviewed the manuscript critically. DE and HCP: supervised the entire project, provided the infrastructure for conducting this research and critically reviewed the manuscript

Funding The authors have not declared a specific grant for this research from any funding agency in the public, commercial or not-for-profit sectors.

Competing interests None declared.

Patient consent for publication Not required.

Provenance and peer review Not commissioned; externally peer reviewed.

Data availability statement Data are available upon reasonable request. Extra data can be accessed via the Dryad data repository at http://datadryad.org/ with the doi: $10.5061 /$ dryad.mpg4f4r06.

Supplemental material This content has been supplied by the author(s). It has not been vetted by BMJ Publishing Group Limited (BMJ) and may not have been peer-reviewed. Any opinions or recommendations discussed are solely those of the author(s) and are not endorsed by BMJ. BMJ disclaims all liability and responsibility arising from any reliance placed on the content. Where the content includes any translated material, BMJ does not warrant the accuracy and reliability of the translations (including but not limited to local regulations, clinical guidelines, terminology, drug names and drug dosages), and is not responsible for any error and/or omissions arising from translation and adaptation or otherwise.

Open access This is an open access article distributed in accordance with the Creative Commons Attribution Non Commercial (CC BY-NC 4.0) license, which permits others to distribute, remix, adapt, build upon this work non-commercially, and license their derivative works on different terms, provided the original work is properly cited, appropriate credit is given, any changes made indicated, and the use is non-commercial. See: http://creativecommons.org/licenses/by-nc/4.0/.

\section{ORCID iDs}

Florian A Schmid http://orcid.org/0000-0002-0862-5027

Ulrike Held http://orcid.org/0000-0003-3105-5840

Sascha Halvachizadeh http://orcid.org/0000-0003-1393-3232

\section{REFERENCES}

1 Almahmoud K, Pfeifer R, Al-Kofahi K, et al. Impact of pelvic fractures on the early clinical outcomes of severely injured trauma patients. Eur J Trauma Emerg Surg 2018;44:155-62.

2 Pape H-C, Zelle B, Lohse R, et al. Evaluation and outcome of patients after polytrauma--can patients be recruited for long-term follow-up? Injury 2006;37:1197-203.

3 Aaran LHC, Him CK, Bong LK. Outcome of Haemodynamically Unstable Open Pelvic Fracture Patients Managed With "3-in-1" Pelvic Damage Control Protocol in a Major Trauma Centre. J Orthop Trauma Rehabil 2018;25:62-8.

4 Mann SM, Banaszek D, Lajkosz K, et al. High-energy trauma patients with pelvic fractures: management trends in Ontario, Canada. Injury 2018;49:1830-40.

5 Matityahu A, Marmor M, Elson JK, et al. Acute complications of patients with pelvic fractures after pelvic angiographic embolization. Clin Orthop Relat Res 2013;471:2906-11.

6 Giannoudis PV, Pape HC. Damage control orthopaedics in unstable pelvic ring injuries. Injury 2004;35:671-7.

7 Stahel PF, Burlew CC, Moore EE. Current trends in the management of hemodynamically unstable pelvic ring injuries. Curr Opin Crit Care 2017;23:511-9.
8 Papakostidis C, Kanakaris NK, Kontakis G, et al. Pelvic ring disruptions: treatment modalities and analysis of outcomes. Int Orthop 2009;33:329-38.

9 Küper MA, Trulson A, Stuby FM, et al. Pelvic ring fractures in the elderly. EFORT Open Rev 2019;4:313-20.

10 Handoll HHG, Cameron ID, Mak JCS. Multidisciplinary rehabilitation for older people with hip fractures. Cochrane Database Syst Rev 2009:CD007125.

11 Strasser DC, Uomoto JM, Smits SJ. The interdisciplinary team and polytrauma rehabilitation: prescription for partnership. Arch Phys Med Rehabil 2008;89:179-81.

12 Blaschko SD, Sanford MT, Schlomer BJ, et al. The incidence of erectile dysfunction after pelvic fracture urethral injury: a systematic review and meta-analysis. Arab J Urol 2015;13:68-74.

13 Johnsen NV, Kaufman MR, Dmochowski RR, et al. Erectile dysfunction following pelvic fracture urethral injury. Sex Med Rev 2018;6:114-23.

14 Horiguchi A. Management of male pelvic fracture urethral injuries: review and current topics. Int J Urol 2019;26:596-607.

15 Shamloul R, Ghanem H. Erectile dysfunction. Lancet 2013;381:153-65.

16 Moher D, Liberati A, Tetzlaff J, et al. Preferred reporting items for systematic reviews and meta-analyses: the PRISMA statement. PLoS Med 2009;6:e1000097.

17 Shamseer L, Moher D, Clarke M, et al. Preferred reporting items for systematic review and meta-analysis protocols (PRISMA-P) 2015: elaboration and explanation. BMJ 2015;350:g7647.

18 Burgess AR, Eastridge BJ, Young JW, et al. Pelvic ring disruptions: effective classification system and treatment protocols. J Trauma 1990;30:848-56.

19 Tile M. Acute pelvic fractures: I. causation and classification. J Am Acad Orthop Surg 1996;4:143-51.

20 Meinberg EG, Agel J, Roberts CS, et al. Fracture and dislocation classification Compendium-2018. J Orthop Trauma 2018;32 Suppl 1:S1-170.

21 Rosen RC, Riley A, Wagner G, et al. The International index of erectile function (IIEF): a multidimensional scale for assessment of erectile dysfunction. Urology 1997;49:822-30.

22 Rhoden EL, Telöken C, Sogari PR, et al. The use of the simplified international index of erectile function (IIEF-5) as a diagnostic tool to study the prevalence of erectile dysfunction. Int J Impot Res 2002;14:245-50.

23 Rosen RC, Cappelleri JC, Smith MD, et al. Development and evaluation of an abridged, 5-item version of the International index of erectile function (IIEF-5) as a diagnostic tool for erectile dysfunction. Int J Impot Res 1999;11:319-26.

24 Ouzzani M, Hammady H, Fedorowicz Z, et al. Rayyan-a web and mobile APP for systematic reviews. Syst Rev 2016;5:210.

25 Whiting PF, Rutjes AWS, Westwood ME, et al. QUADAS-2: a revised tool for the quality assessment of diagnostic accuracy studies. Ann Intern Med 2011;155:529-36.

26 Higgins JPT TJ, Chandler J, Cumpston M, eds. Cochrane Handbook for Systematic Reviews of Interventions version 6.0 (updated July 2019). Cochrane, 2019.

27 Wan X, Wang W, Liu J, et al. Estimating the sample mean and standard deviation from the sample size, median, range and/or interquartile range. BMC Med Res Methodol 2014;14:135.

28 Luo D, Wan X, Liu J, et al. Optimally estimating the sample mean from the sample size, median, mid-range, and/or mid-quartile range. Stat Methods Med Res 2018;27:1785-805.

29 Weir CJ, Butcher I, Assi V, et al. Dealing with missing standard deviation and mean values in meta-analysis of continuous outcomes: a systematic review. BMC Med Res Methodol 2018;18:25.

30 R Core Team. R: a language and environment for statistical computing. Austria: R Foundation for Statistical Computing V, 2017. https://www.R-project.org/

31 Fanjalalaina Ralahy M, Parfaite Randriantsoa M, Rakototiana A, et al. Incidence of erectile dysfunction in pelvic ring injuries: study of 48 patients at the antananarivo Hospital, Madagascar. Orthop Traumatol Surg Res 2019;105:885-8.

32 Pastor T, Tiziani S, Kasper CD, et al. Quality of reduction correlates with clinical outcome in pelvic ring fractures. Injury 2019;50:1223-6.

33 Schmitz P, Lüdeck S, Baumann F, et al. Patient-related quality of life after pelvic ring fractures in elderly. Int Orthop 2019;43:261-7.

34 Brouwers L, Lansink KWW, de Jongh MAC. Quality of life after pelvic ring fractures: a cross-sectional study. Injury 2018;49:812-8.

35 Montgomery B, Husmann D. PD44-07 pelvic fracture urethral distraction defect (PFUDD) with associated rectal injury: a review of acute and definitive urologic management with long term outcomes. J Urol 2016;195:e1000. 
36 Gdeh D, Haffejee M, Nel M. Frequency of erectile dysfunction following pelvic fracture among patients admitted to two Wits teaching hospitals, South Africa. Sudan Journal of Medical Sciences 2018;13:144-67.

37 King J. Impotence after fractures of the pelvis. Journal of Bone \& Joint Surgery - American Volume;57:1107-9.

38 Metze M, Tiemann AH, Josten C. Male sexual dysfunction after pelvic fracture. Journal of Trauma-Injury Infection \& Critical Care;63:394-401.

39 Yafi FA, Huynh LM, Ahlering T, et al. What Is a "Validated Questionnaire"? A Critical Review of Erectile Function Assessment. J Sex Med 2020;17:849-60.

40 Ceylan $\mathrm{H}-\mathrm{H}$, Kuyucu E, Erdem R, et al. Does pelvic injury trigger erectile dysfunction in men? Chin J Traumatol 2015;18:229-31.

41 Duramaz A, Ilter MH, Yıldız Sükrü, et al. The relationship between injury mechanism and sexual dysfunction in surgically treated pelvic fractures. Eur J Trauma Emerg Surg 2020;46:807-16.

42 Harwood PJ, Grotz M, Eardley I, et al. Erectile dysfunction after fracture of the pelvis. J Bone Joint Surg Br 2005;87:281-90.

43 Armenakas NA, McAninch JW, Lue TF, et al. Posttraumatic impotence: magnetic resonance imaging and duplex ultrasound in diagnosis and management. J Urol 1993;149:1272-5.

44 Robinson LQ, Woodcock JP, Stephenson TP. Results of investigation of impotence in patients with overt or probable neuropathy. $\mathrm{Br} \mathrm{J} \mathrm{Urol}$ 1987;60:583-7.

45 Ellison M, Timberlake GA, Kerstein MD. Impotence following pelvic fracture. J Trauma 1988;28:695-6.

46 Shenfeld OZ, Kiselgorf D, Gofrit ON, et al. The incidence and causes of erectile dysfunction after pelvic fractures associated with posterior urethral disruption. J Urol 2003;169:2173-6.

47 Munarriz RM, Yan QR, ZNehra A, et al. Blunt trauma: the pathophysiology of hemodynamic injury leading to erectile dysfunction. J Urol 1995;153:1831-40.

48 Mark SD, Keane TE, Vandemark RM, et al. Impotence following pelvic fracture urethral injury: incidence, aetiology and management. Br J Urol 1995;75:62-4.

49 Blaschko SD, Sanford MT, Schlomer BJ, et al. The incidence of erectile dysfunction after pelvic fracture urethral injury: a systematic review and meta-analysis. Arab J Urol 2015;13:68-74.

50 Anger JT, Sherman ND, Dielubanza E, et al. Erectile function after posterior urethroplasty for pelvic fracture-urethral distraction defect injuries. BJU Int 2009;104:1126-9.

51 Barratt RC, Bernard J, Mundy AR, et al. Pelvic fracture urethral injury in males-mechanisms of injury, management options and outcomes. Transl Androl Urol 2018;7:S29-62.

52 Light A, Gupta T, Dadabhoy M, et al. Outcomes following primary realignment versus suprapubic cystostomy with delayed urethroplasty for pelvic Fracture-Associated posterior urethral injury: a systematic review with meta-analysis. Curr Urol 2019;13:113-24.

53 Scarberry K, Bonomo J, Gómez RG. Delayed posterior urethroplasty following pelvic fracture urethral injury: do we have to wait 3 months? Urology 2018;116:193-7.

54 Zou Q, Zhou S, Zhang K, et al. The immediate management of pelvic fracture urethral Injury-Endoscopic realignment or cystostomy? J Urol 2017;198:869-74

55 Mosquera Rey V, Fernández C, Zanabili A, et al. Endovascular repair of iliac vein laceration associated with complex pelvic fracture. Ann Vasc Surg 2019;54:4.

56 Báča V, Báčová T, Grill R, et al. Pudendal nerve in pelvic bone fractures. Injury 2013;44:952-6.

57 Wright JL, Nathens AB, Rivara FP, et al. Specific fracture configurations predict sexual and excretory dysfunction in men and women 1 year after pelvic fracture. J Urol 2006;176:1540-5. discussion 45.
58 Wright JL, Wessells HB, Nathens AB, et al. 330: sexual and excretory dysfunction one year after pelvic fracture. J Urol 2005;173:91.

59 Harvey-Kelly KF, Kanakaris NK, Obakponovwe O, et al. Quality of life and sexual function after traumatic pelvic fracture. J Orthop Trauma 2014;28:28-35.

60 Harvey-Kelly KF, Kanakaris NK, Eardley I, et al. Sexual function impairment after high energy pelvic fractures: evidence today. J Urol 2011;185:2027-34

61 Delle Rose A, Stomaci N, Pironti M. Impotence due to pelvic trauma: treatment with papaverine and PGE1. Acta Urologica Italica 1992;6:27-8

62 Shenfeld OZ, Gofrit ON, Gdor Y, et al. The role of sildenafil in the treatment of erectile dysfunction in patients with pelvic fracture urethral disruption. J Urol 2004;172:2350-2.

63 Ventimiglia E, Capogrosso P, Montorsi F, et al. The safety of phosphodiesterase type 5 inhibitors for erectile dysfunction. Expert Opin Drug Saf 2016;15:141-52.

64 Goldstein I, Tseng L-J, Creanga D, et al. Efficacy and safety of sildenafil by age in men with erectile dysfunction. $J$ Sex Med 2016;13:852-9.

65 Liao X, Qiu S, Bao Y, et al. Comparative efficacy and safety of phosphodiesterase type 5 inhibitors for erectile dysfunction in diabetic men: a Bayesian network meta-analysis of randomized controlled trials. World J Urol 2019;37:1061-74.

66 Gong B, Ma M, Xie W, et al. Direct comparison of tadalafil with sildenafil for the treatment of erectile dysfunction: a systematic review and meta-analysis. Int Urol Nephrol 2017;49:1731-40.

67 Liu C, Lopez DS, Chen M, et al. Penile rehabilitation therapy following radical prostatectomy: a meta-analysis. J Sex Med 2017;14:1496-503.

68 Philippou YA, Jung JH, Steggall MJ, et al. Penile rehabilitation for postprostatectomy erectile dysfunction. Cochrane Database Syst Rev 2018;10:CD012414.

69 Qiu S, Tang Z, Deng L, et al. Comparisons of regular and on-demand regimen of $P E D 5-I s$ in the treatment of $E D$ after nerve-sparing radical prostatectomy for prostate cancer. Sci Rep 2016;6:32853.

70 Nieto-Esquivel A, Delgado-Balderas R, Robles-Torres Jl, et al. [Use of tadalafil in the rehabilitation of patients with a history of posterior urethral injury in the context of pelvic fracture]. Rev Int Androl 2018;16:15-19.

71 Fu Q, Sun X, Tang C, et al. An assessment of the efficacy and safety of sildenafil administered to patients with erectile dysfunction referred for posterior urethroplasty: a single-center experience. J Sex Med 2012;9:282-7

72 Peng J, Zhang Z, Gao B, et al. 103 effect of daily sildenafil on patients with absent nocturnal erections due to pelvic fracture urethral disruption: a single-center experience. J Sex Med 2017:14:S25.

73 Qiang F, Xianjun S, Chenye T. The efficacy and safety of sildenafil on treatment of patients with erectile dysfunction referred for posterior urethroplasty: a single center experience. Chinese Journal of Andrology 2011;25:27-31.

74 Wang C-J, Lu Y-M, Li C-C, et al. Low-Intensity shock wave therapy ameliorates erectile dysfunction in men with pelvic fractures associated with urethral injury. Int J Impot Res 2019;31:218-22.

75 Zhang D-L, Chen Z, Wang F-X, et al. Adding a vacuum erection device to regular use of tadalafil improves penile rehabilitation after posterior urethroplasty. Asian J Androl 2019;21:582-6.

76 Song L, Fu Q. MP91-18 the role of vacuum erection devices in penile rehabilitation after posterior urethral anastomotic urethroplasty:a pilot study. J Urol 2017;197:e1224-5.

77 Hellstrom WJG, Montague DK, Moncada I, et al. Implants, mechanical devices, and vascular surgery for erectile dysfunction. $J$ Sex Med 2010;7:501-23. 